\title{
Towards simulation of germinal matrix hemorrhage as a complication of premature birth
}

\author{
Renée Lampe*, Varvara Turova, Tobias Blumenstein, Ana Alves-Pinto \\ Cerebral Palsy and Children Neuro-Orthopedics Unit, Orthopedic Department, Clinic "Rechts der Isar", Technical University of \\ Munich, Munich, Germany \\ Email: ${ }^{*}$ renee.lampe@1rz.tu-muenchen.de
}

Received 16 September 2013; revised 15 October 2013; accepted 23 October 2013

Copyright (C) 2013 Renée Lampe et al. This is an open access article distributed under the Creative Commons Attribution License, which permits unrestricted use, distribution, and reproduction in any medium, provided the original work is properly cited.

\begin{abstract}
The germinal matrix being an accumulation of immature blood vessels in the premature infant brain is known to be the main cause of the intracranial hemorrhage. To investigate the injuring mechanism to the blood vessels of the germinal matrix, a modeling scenario that consists of three basic steps is proposed. First, the cerebral blood flow that depends on autoregulation, $\mathrm{CO}_{2}$ reactivity, and variations of intracranial pressure is modeled. Second, the chaotic blood vessel network of the germinal matrix is generated, and blood pressures in the vessels of this network are computed dependent on the outcome of the first step. In the third step, the pressures computed on the second step are used in finite element simulations of separate blood vessels of the germinal matrix to detect critical values for vessels impairment.
\end{abstract}

Keywords: Cerebral Palsy; Germinal Matrix Hemorrhage; Injuring Factors; Mathematical Model; Computer Simulation

\section{RISK FACTORS FOR GERMINAL MATRIX HEMORRHAGE}

A premature birth before completion of the 37th pregnancy week increases the risk of intracranial hemorrhage. According to [1], 85 of 155 newborn infants with the birth weight less than 1500 gram developed an intracranial hemorrhage within the first 24 hours of life. Another 37 had an intracranial hemorrhage after 24 hours of age. The place of the brain bleeding is always the germinal matrix of the immature brain. The germinal matrix consists of richly vascularized neuroepithelial cells and is located ventrolateral to the lateral ventricle. The vulnerability of the germinal matrix is primarily due to the pre-

\footnotetext{
${ }^{*}$ Corresponding author.
}

capillary arteriolar-venular anastomoses and the absence of muscle and collagen layers in its immature blood vessels. Also changes in oxygen concentration might be damaging for endothelial cells of the germinal matrix because increased metabolic activity in this area leads to high oxygen consumption (see e.g. [2]).

Some risk and protective factors for intracranial hemorrhage are described in [3]. Antenatal steroid therapy, female gender of the infant, increasing gestational age and birth weight are reported as protective, whereas lower gestational age and mother bleedings shortly before the child birth are considered as risk factors. In [4], acute amnion inflammation, volume expansion at delivery in the first 3 days of life and magnesium sulfate anti-contraction medication are indicated as additional risk factors of early intracranial hemorrhage.

The consequences of the low gestational age and preterm birth are acute changes in $\mathrm{CO}_{2}$ and blood pressure, impaired cerebral autoregulation, and increased cerebral venous pressure (CVP) due to e.g. pneumothorax, mechanical or any pressure ventilation, skull deformations, and venous anatomy in germinal matrix $[5,6]$. Both variations in $\mathrm{CO}_{2}$ blood content and impaired cerebral autoregulation, which is a dynamic and evolving process, lead to cerebral blood flow (CBF) pressure-passivity, which, in turn, causes CBF fluctuations [6-9]. The increase of CVP reduces the cerebral perfusion pressure (CPP), which is the difference between the mean arterial pressure (MAP) and cerebral venous pressure $(\mathrm{CPP}=$ MAP - CVP). This can reduce the global CBF down to $20 \%$. Note that CVP is usually replaced by intracranial pressure (ICP) because CVP is difficult to measure.

Fluctuations in CBF are considered as a main cause of germinal matrix hemorrhage [5], whereas hypotension $(20 \%-45 \%$ lower in premature infants) remains under discussion.

Prevention of neonatal intraventricular hemorrhage includes different prenatal and postnatal strategies like ef- 
forts against preterm delivery, transfer of high risk mothers to tertiary care centers, antenatal maternal steroid use, and optimal resuscitation regarding especially minimization of cerebral blood flow fluctuation [10]. In [11], a pharmacologic therapy with phenobarbital and vitamin $\mathrm{K}$ during antenatal period is mentioned as having significantly reduced severe grades of intraventricular hemorrhage. Spinillo et al. [12] note that risk factors for neonatal germinal matrix hemorrhage are different from those for intraventricular hemorrhage. Better understanding of how both of these events are originated remains a very actual task.

\section{MATHEMATICAL MODELING AND SIMULATION OF BLEEDINGS IN THE GERMINAL MATRIX}

This paper outlines our aim to mathematically simulate the development and occurrence of bleedings in the germinal matrix. The following three-stage modeling procedure is proposed.

1) Simulation of the interaction between the autoregulation, $\mathrm{CO}_{2}$ reactivity and ICP using electric circuit ana$\log$ models similar to those developed in $[13,14]$. The varying $\mathrm{CBF}$ obtained as the output of this simulation will be used as the input data for a mathematical model of the germinal matrix blood vessel system.

2) Simulation of the germinal matrix blood vessel system, for which the mathematical model of Anderson and Chaplain [15] that describes the formation of a realistic capillary sprout network will be applied. With this model, the processes of sprout branching, anastomosis (loop formation) and cell proliferation can be accounted for (see e.g. [16]). Additionally, the dependence of vessels diameters on the partial $\mathrm{CO}_{2}$ content will be considered. The outcome of the simulation will be in particular the dependency of the blood pressure on the partial $\mathrm{CO}_{2}$ pressure in every vessel of the generated network. Figure 1 shows an example of such dependencies for three types of vessels of a deterministic blood vessel network described in [17].

3) Analysis of the impact of pressure variations in the mechanical properties of different types of vessels like arterioles, veins, venules with accounting for peculiarities of germinal matrix (vessels with no muscle and collagen layers, with relatively large diameters and thin walls). The vessels will be modeled as tubes made of materials with complex elasto-plastic properties using finite element techniques. For different types of vessels, dependency of basic mechanical characteristics like stress, strain and deformation on the pressure will be studied, and damaging pressure values will be detected. Figure 2 shows an example of a finite element computation for a blood vessel model.

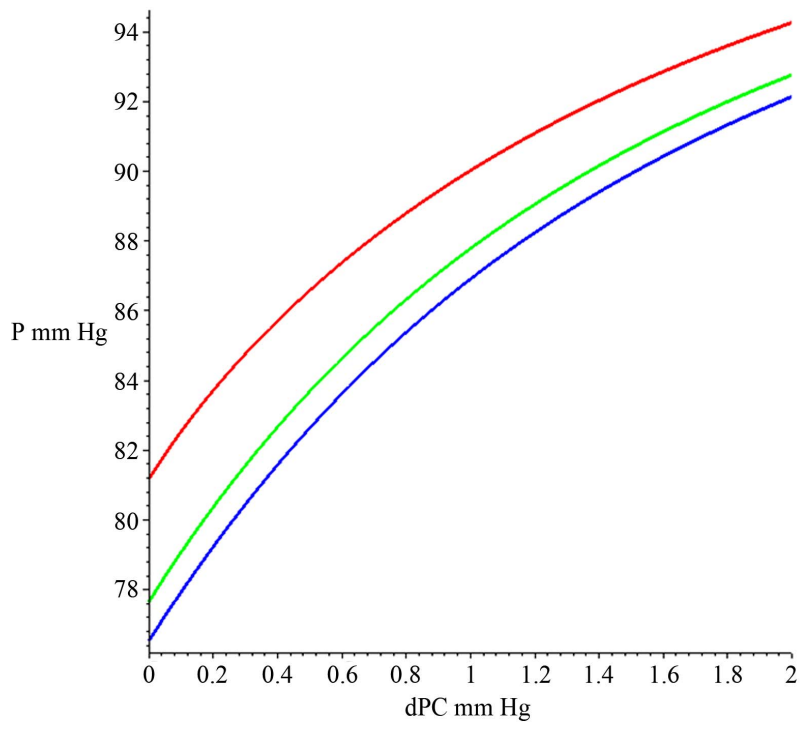

Figure 1. Blood pressure versus partial $\mathrm{CO}_{2}$ pressure for arterioles (red line), capillaries (green line), and venules (blue line).
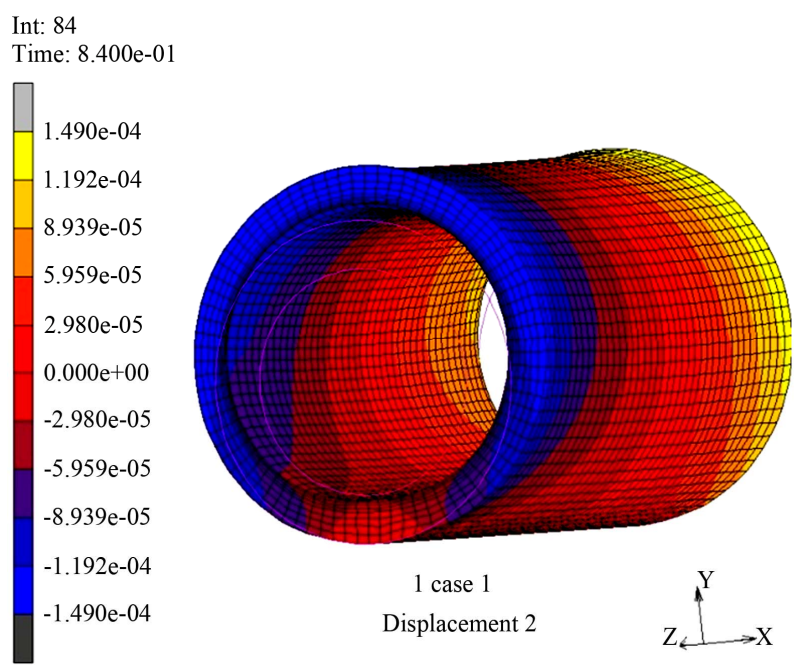

Figure 2. Example of a blood vessel simulation performed with Marc/Mentat solver.

\section{CONCLUSION}

With this 3-stage model, the role of different factorsautoregulation mechanisms, $\mathrm{CO}_{2}$ reactivity, and ICP in the occurrence of germinal matrix hemorrhages will be quantitatively estimated. This will create a basis for practical recommendations on the prevention of intraventricular hemorrhages in premature infants.

\section{REFERENCES}

[1] Bada, H.S., Korones, S.B., Anderson, G.D., Magill, H.L. and Wong S.P. (1984) Obsteric factors and relative risk of neonatal layer/intraventricular hemorrhage. American Journal of Obstetrics \& Gynecology, 148, 798-804. http://dx.doi.org/10.1016/0002-9378(84)90571-4 
[2] Huang, B.Y. and Castillo, M. (2008) Hypoxic-ischemic brain injury: Imaging findings from birth to adulthood. RadioGraphics, 28, 417-439. http://dx.doi.org/10.1148/rg.282075066

[3] Shankaran, S., Bauer, C.R., Bain, R., Wright, L.L. and Zachary, J. (1996) Prenatal and perinatal risk and protective factors for neonatal intracranial hemorrhage. Archives of Pediatrics and Adolescent Medicine, 150, 491497.

http://dx.doi.org/10.1001/archpedi.1996.02170300045009

[4] Salafia, C.M., Minior, V.K., Rosenkrantz, T.S., Pezullo, J.C., Popek, E.J., Cusick, W. and Vintzileos, A.M. (1995) Maternal, placental, and neonatal associations with early germinal matrix/intraventricular hemorrhage in infants born before 32 weeks' gestation. American Journal of Perinatology, 12, 429-436.

http://dx.doi.org/10.1055/s-2007-994514

[5] Volpe, J.J. (2008) Neurology of the newborn. Saunders, Elsevier.

[6] Ballabh, P. (2010) Intraventricular hemorrhage in premature infants: Mechanism of disease. Pediatric Research, 67, 1-8. http://dx.doi.org/10.1203/PDR.0b013e3181c1b176

[7] Soul, J.S., Hammer, P.E., Tsuji, M., Saul, J.P., Bassan, H., Limperopoulos, C., Disalvo, D.N., Moore, M., Akins, P., Ringer, S., Volpe, J.J., Trachtenberg, F. and du Plessis, A.J. (2007) Fluctuating pressure-passivity is common in the cerebral circulation of sick premature infants. Pediatric Research, 61, 467-473.

http://dx.doi.org/10.1203/pdr.0b013e31803237f6

[8] Greene, N.H. and Lee, L.A. (2012) Modern and evolving understanding of cerebral perfusion and autoregulation. Advances in Anesthesia, 30, 97-129. http://dx.doi.org/10.1016/j.aan.2012.08.003

[9] O'Leary, H., Gregas, M.C., Limperopoulos, C., Zaretskaya, I., Bassan, H., Soul, J.S., Di Salvo, D.N. and du Plessis, A.J. (2009) Elevated cerebral pressure passivity is associated with prematurity-related intracranial hemorrhage. Pediatrics, 124, 302-309. http://dx.doi.org/10.1542/peds.2008-2004
[10] Wells, J.T. and Ment, L.R. (1995) Prevention of intraventricular hemorrhage in preterm infants. Early Human Development, 42, 209-233. http://dx.doi.org/10.1016/0378-3782(95)01651-I

[11] Morales, W.J. (1991) Antenatal therapy to minimize neonatal intraventricular hemorrhage. Clinical Obstetrics and Gynecology, 34, 328-335. http://dx.doi.org/10.1097/00003081-199106000-00014

[12] Spinillo, A., Ometto, A., Bottino, R., Piazzi, G., Lasci, A. and Rondini, G. (1995) Antenatal risk factors for germinal matrix hemorrhage and intraventricular hemorrhage in preterm infants. European Journal of Obstetrics \& Gynecology and Reproductive Biology, 60, 13-19. http://dx.doi.org/10.1016/0028-2243(95)02052-7

[13] Ursino, M. and Lodi, C.A. (1998) Interaction among autoregulation, $\mathrm{CO}_{2}$ reactivity and intracranial pressure: A mathematical model. American Journal of Physiology-Heart and Circulatory Physiology, 274, H1715H1728.

[14] Alastruey, J., Moore, S.M., Parker, K.H., David, T., Peiró, J. and Scherwin, S.J. (2008) Reduced modeling of blood flow in cerebral circulation: Coupling 1-D, 0-D and cerebral auto-regulation models. International Journal for Numerical Methods in Fluids, 56, 1061-1067. http://dx.doi.org/10.1002/fld.1606

[15] Anderson, A.R. and Chaplain, M.A. (1998)Continuous and discrete mathematical models of tumor-induced angiogenesis. Bulletin of Mathematical Biology, 60, 857899. http://dx.doi.org/10.1006/bulm.1998.0042

[16] McDougall, S.R., Anderson, A.R.A., Chaplain, M.A.J. and Sherratt, J.A. (2002) Mathematical modelling of flow through vascular networks: Implications for tumour-induced angiogenesis and chemotherapy strategies. Bulletin of Mathematical Biology, 64, 673-702. http://dx.doi.org/10.1006/bulm.2002.0293

[17] Piechnik, S.K., Chiarelli, P.A. and Jezzard, P. (2008) Modelling vascular reactivity to investigate the basis of the relationship between cerebral blood volume and flow under $\mathrm{CO}_{2}$ manipulation. NeuroImage, 39, 107-118. http://dx.doi.org/10.1016/j.neuroimage.2007.08.022 